\title{
Combination of sorafenib and everolimus impacts therapeutically on adrenocortical tumor models
}

\author{
Barbara Mariniello, Antonio Rosato,2, Gaia Zuccolotto ${ }^{1}$, Beatrice Rubin, \\ Maria Verena Cicala, Isabella Finco, Maurizio lacobone ${ }^{3}$, Anna Chiara Frigo ${ }^{4}$, \\ Ambrogio Fassina ${ }^{5}$, Raffaele Pezzani and Franco Mantero
}

\author{
Endocrinology Unit, Department of Medicine, University of Padua, Via Ospedale Civile 105, 35128 Padua, Italy \\ ${ }^{1}$ Department of Surgery, Oncology and Gastroenterology, University of Padua, Via Gattamelata 64, 35128 Padua, Italy \\ ${ }^{2}$ Istituto Oncologico Veneto IRCCS, Via Gattamelata 64, 35128 Padua, Italy \\ ${ }^{3}$ Endocrine Surgery Unit, Department of Surgery, Oncology and Gastroenterology, University of Padua, Via Giustiniani 2, 35128 \\ Padua, Italy \\ ${ }^{4}$ Department of Environmental Medicine and Public Health, University of Padua, Via Loredan 18, Padua, Italy \\ ${ }^{5}$ Surgical Pathology and Cytopathology Unit, Department of Diagnostic Medical Sciences and Special Therapies, University of \\ Padua, Via Gabelli 61, 35100 Padua, Italy
}

(Correspondence should be addressed to R Pezzani; Email: raffaele.pezzani@unipd.it)

\begin{abstract}
Treatment options are insufficient in patients with adrenocortical carcinoma (ACC). Based on the efficacy of sorafenib, a tyrosine kinase inhibitor, and everolimus, an inhibitor of the mammalian target of rapamycin in tumors of different histotype, we aimed at testing these drugs in adrenocortical cancer models. The expression of vascular endothelial growth factor and its receptors (VEGFR1-2) was studied in 18 ACCs, 33 aldosterone-producing adenomas, 12 cortisol-producing adenomas, and six normal adrenal cortex by real-time PCR and immunohistochemistry and by immunoblotting in SW13 and H295R cancer cell lines. The effects of sorafenib and everolimus, alone or in combination, were tested on primary adrenocortical cultures and SW13 and H295R cells by evaluating cell viability and apoptosis in vitro and tumor growth inhibition of tumor cell line xenografts in immunodeficient mice in vivo. VEGF and VEGFR1-2 were detected in all samples and appeared over-expressed in two-thirds of ACC specimens. Dose-dependent inhibition of cell viability was observed particularly in SW13 cells after $24 \mathrm{~h}$ treatment with either drug; drug combination produced markedly synergistic growth inhibition. Increasing apoptosis was observed in tumor cells treated with the drugs, particularly with sorafenib. Finally, a significant mass reduction and increased survival were observed in SW13 xenograft model undergoing treatment with the drugs in combination. Our data suggest that an autocrine VEGF loop may exist within ACC. Furthermore, a combination of molecularly targeted agents may have both antiangiogenic and direct antitumor effects and thus could represent a new therapeutic tool for the treatment of ACC.
\end{abstract}

Endocrine-Related Cancer (2012) 19 527-539

\section{Introduction}

Adrenocortical masses are common tumors, with a prevalence of at least $3 \%$ in the population over the age of 50 years; they are incidentally discovered up to $5 \%$ on abdominal imaging and $15 \%$ of patients at autopsy (Grumbach et al. 2003). In contrast, adrenocortical carcinoma (ACC) is a rare malignancy (incidence 1-2 cases per million population) with a heterogeneous presentation and generally poor prognosis (Allolio \& Fassnacht 2006).

Despite some recent progress, our understanding of the biology of adrenocortical tumors (ACTs) is still incomplete. Adrenocortical tumorigenesis appears to be a multistep process, resulting from sequential genetic alterations leading to progression from normal to adenomatous and eventually malignant phenotype 
(de Fraipont et al. 2005). Angiogenesis plays a major role in cancer growth and metastasis. Differences in angiogenesis and the balance between angiogenic growth factors and inhibitors may play a role in determining the observed variations in tumor behavior. The angiogenic status of a tumor can be assessed by studying vascular endothelial growth factor (VEGF), an endothelial cell mitogen (Leung et al. 1989, Crew et al. 1997, Shibusa et al. 1998). Previous studies showed that the angiogenic phenotype of human ACC is characterized by $V E G F$ over-expression (Bernini et al. 2002), with VEGF mRNA increasing in cultured adrenocortical cells after the treatment with ACTH or cAMP (Heikkilä et al. 2000). Moreover, circulating VEGF levels are significantly elevated in endocrine hypertension due to glucocorticoid excess (Zacharieva et al. 2005).

VEGF acts on endothelial cells in a paracrine mode after its release from other sources such as tumor cells or in an autocrine manner from VEGF-producing endothelial cells. Following the binding to VEGF receptor 2 (VEGFR2), VEGF mediates its effects on proliferation, survival, adhesion, migration, and gene expression in endothelial cells (Ferrara et al. 2003). Moreover, VEGF acts in an autocrine manner as a growth and survival factor for the tumor cells that express the VEGFR (Bachelder et al. 2001, Masood et al. 2001, Wey et al. 2004).

New therapies using VEGFR tyrosine kinase inhibitors have been used in metastatic renal cell carcinoma (Wilhelm et al. 2008) and hepatocellular carcinoma (Keating \& Santoro 2009). Sorafenib acts on multiple tyrosine kinases, including VEGFR2 (Wilhelm et al. 2004, 2006), and it can directly inhibit tumor cell growth via Raf-MEK-ERK signaling (Liu et al. 2006). Sorafenib also has been reported to induce apoptosis in a variety of tumor cells through downregulation of Mcl-1 (Rahmani et al. 2005).

Other drugs, like rapamycin, show antiangiogenic activities linked to a decrease in production of VEGF and to a markedly inhibited response of vascular endothelial cells to stimulation by VEGF (Guba et al. 2002). Everolimus, a derivative of rapamycin, acts as a signal transduction inhibitor. Its molecular target is the mammalian target of rapamycin (mTOR), a component in the PI3K/Akt/mTOR pathway known to be very frequently activated in human cancers (Houghton 2010) and a frequent characteristic of worsening prognosis, resistance to treatment, extension of disease, and progression. Everolimus has been shown to suppress expression of hypoxia-inducible factor-1 (HIF1) and VEGF in cultured tumor cells and also to reduce blood vessel density in several different experimental tumor models (Shinohara et al. 2005, Mabuchi et al. 2007a,b). Moreover, everolimus has been recently reported to significantly inhibit proliferation of adrenocortical cell lines (Doghman et al. 2010). Interestingly, combination therapy, as in hepatocellular carcinoma, has generally met with greater clinical success than monotherapy (Huynh et al. 2009).

The aim of this study was to estimate the expression of $V E G F$ and its receptors in ACT and to evaluate the effect of sorafenib and everolimus, alone or in combination, on adrenocortical cell lines, primary ACT cell cultures, and xenograft models of ACC.

\section{Materials and methods}

\section{Patients and biological specimens}

ACT tissues were obtained surgically from 18 patients with ACC, 33 with aldosterone-producing adenomas (APA), and 11 with cortisol-producing adenomas (CPAs); six adrenocortical normal (NA) samples were obtained from renal transplantation procedures. The etiology of each adrenocortical mass, clinical diagnoses, malignancy, and staging were established as described (Mariniello et al. 2010). Of 18 ACC patients, three were stage II and the others stage IV (Table 1). All patients (including those providing normal samples) gave written informed consent to the

Table 1 Adrenocortical tumor patient clinical data $(n=63)$

\begin{tabular}{ll}
\hline Parameter & Value \\
\hline Adrenocortical adenomas (ACA) & 45 \\
Female/male & $29 / 19$ \\
Median age (range) & 44 years (27-68 years) \\
Function & \\
Cortisol producing & 9 \\
Cortisol and androgen producing & 3 \\
Aldosterone producing & 33 \\
Testosterone & 0 \\
Nonfunctioning & 0 \\
Adrenocortical carcinomas (ACC) & 18 \\
Female/male & $11 / 7$ \\
Median age (range) & 50 years (1-68 years) \\
Function & \\
Cortisol producing & 4 \\
Cortisol and androgen producing & 4 \\
Aldosterone producing & 0 \\
Testosterone & 0 \\
Nonfunctioning & 10 \\
Median tumor size (range) & 80 mm (40-150 mm) \\
Tumor stage (ENSAT stage) & \\
I & 0 \\
II & 3 \\
III & 0 \\
IV & 15 \\
\hline
\end{tabular}


collection and use of adrenal tissue for research purposes, and the study was approved by the Local Ethics Committee. After surgery, a sample of tissue was collected in RNA-Later (Pierce, Rockford, IL, USA) and stored at $-20{ }^{\circ} \mathrm{C}$ for expression analysis; the remainder was used for primary cell culture and/or immunohistochemistry (IHC).

\section{Adrenocortical cell cultures}

H295R (primary) and SW13 (metastatic) ACC cell lines were obtained from the American Type Culture Collection (ATCC, Rockville, MD, USA) and cultured in DMEM-F12 (Sigma-Aldrich) supplemented with $5 \%(\mathrm{H} 295 \mathrm{R})$ and 10\% (SW13) fetal bovine serum (FBS), insulin $(1 \mu \mathrm{g} / \mathrm{ml})$, L-glutamine $(2 \mathrm{mM})$, transferrin $(1 \mu \mathrm{g} / \mathrm{ml})$, selenium $(1 \mathrm{ng} / \mathrm{ml})$, and antibiotics $(100 \mu \mathrm{g} / \mathrm{ml}$ streptomycin sulfate). Eight primary cell cultures were studied, five ACCs and three APA, as described previously (Mariniello et al. 2010). All experiments were performed on exponentially growing cells, routinely maintained as monolayer cultures. As a method of authentication, the karyotype of cell lines and the steroid secretion profile of H295R cells were periodically tested.

\section{Isolation of RNA and CDNA synthesis}

Total RNA was extracted from H295R and SW13 cells and from 69 human adrenocortical samples with an RNeasy Mini Kit (Qiagen) in accordance with the manufacturer's protocol and stored at $-80{ }^{\circ} \mathrm{C}$. Concentration and integrity of RNA, and cDNA synthesis, were checked and performed as described (Mariniello et al. 2010).

\section{Real-time PCR}

The following primers for VEGF, VEGFRl (FLT1), $V E G F R 2(K D R)$, and $\beta$-actin genes were designed by Primer Express Software (Applied Biosystems, Foster City, CA, USA): VEGF, F: 5'-GAAGTGGTGAAGTTCATGGATGTCT- $3^{\prime}$ and R: 5'-TCAGGGTACTCCTGGAAGATGTC-3'; VEGFR1, F: 5'-TCTGGCAGCCCCTGTAACCA-3' and R: 5'-TCCAGGATAAAGGACTCTTCATTATTG- $3^{\prime}$; VEGFR2, F: $5^{\prime}$-CACCACTCAAACGCTGACATGTA- $3^{\prime}$ and R: 5'-CCAACTGCCAATACCAGTGGAT- $3^{\prime}$; and $\beta$-actin, F: $5^{\prime}$-GGGACGACATGGAGAAAATCTG$3^{\prime}$ and R: 5'-CACGCAGCTCATTGTAGAAGGT-3'. Final primer concentration was set at $150 \mathrm{nM}$ with the exception of those for $\beta$-actin $(30 \mathrm{nM})$. Real-time PCR protocols were described as previously (Mariniello et al. 2010). Data were obtained as $C_{\mathrm{t}}$ values according to the guidelines and used to determine $\Delta C_{\mathrm{t}}$ values
$\left(\Delta C_{\mathrm{t}}=C_{\mathrm{t}}\right.$ of the target gene minus $C_{\mathrm{t}}$ of the housekeeping gene). The equation $2^{\Delta \Delta C_{t}}$ was used to calculate the fold changes in gene expression between two categories of samples (e.g. ACC vs NA).

\section{Immunohistochemistry}

IHC was performed in ten ACCs, ten APA, and three CPA as described (Albiger et al. 2007). VEGF and VEGFR2 antibodies (Santa Cruz Biotechnology, Santa Cruz, CA, USA) were diluted at 1:400 and 1:50, respectively, in primary antibody diluent. As a negative control, the primary antibody incubation step was omitted; normal human kidney and human colon carcinoma were used as positive controls for VEGF and VEGFR2 respectively.

\section{Chemical compounds}

Sorafenib tosylate (Nexavar) was a gift from Bayer Corporation and everolimus (RAD001) from Novartis. Compounds were dissolved in 100\% dimethyl sulfoxide (DMSO) (Sigma) and diluted with DMEM-F12 to the desired final concentration for in vitro studies.

\section{Adrenocortical cell proliferation studies}

H295R, SW13, and primary cells isolated from eight ACTs were plated in 96-well tissue culture dishes at a density of $5 \times 10^{3}$ cells/well in supplemented medium and used for viability studies employing the 3-(4,5-dimethylthiazol-2-yl)-2,5-diphenyltetrazolium bromide (MTT) assay (Sigma). After 2 days of culture, cells were maintained overnight in low serum medium (DMEM-F12 with $0.1 \%$ FBS) and drug incubation was carried out at different concentrations of everolimus and sorafenib, alone and in combination (from $1 \mathrm{nM}$ to $10 \mu \mathrm{M})$. After 24 and $72 \mathrm{~h}$, MTT $(2.5 \mathrm{mg} / \mathrm{ml}$ in PBS) was added for additional $3 \mathrm{~h}$. The percentage of cell survival was calculated as described (Mariniello et al. 2010). All experiments were performed in quadruplicate.

\section{Immunoprecipitation and western blot analysis}

For immunoprecipitation (IP) analysis, H295R and SW13 cells were treated with sorafenib $(5 \mu \mathrm{M})$ for $6 \mathrm{~h}$. During the last $20 \mathrm{~min}$ of drug incubation, cells were stimulated with VEGF (Sigma-Aldrich) at $50 \mathrm{ng} / \mathrm{ml}$. For protein extraction, cells were treated with lysis buffer (40 mM HEPES, $120 \mathrm{mM}$ sodium chloride, $10 \mathrm{mM}$ sodium pyrophosphate, $10 \mathrm{mM}$ sodium glycerophosphate, $1 \mathrm{mM}$ EDTA, $50 \mathrm{mM}$ sodium fluoride, $0.5 \mathrm{mM}$ sodium orthovanadate, and $1 \%$ Triton $\mathrm{X}-100$ ) containing a protease inhibitor cocktail (Sigma-Aldrich) for $1 \mathrm{~h}$ at $4{ }^{\circ} \mathrm{C}$. After centrifugation, 
supernatants were immunoprecipitated with antiVEGFR2 antibody and resuspended in Protein A/G PLUS Agarose (Santa Cruz Biotechnology) following the manufacturer's protocol. Samples were subjected to SDS-PAGE, evaluated by western blot (WB) analysis (as described below), and incubated with anti-phospho-VEGFR2 antibody. Protein content was quantified by colorimetric assay (Kit Detergent compatible assay Bio-Rad); $10 \mu \mathrm{g}$ protein was separated on SDS/PAGE and electroblotted onto nitrocellulose membrane (Bio-Rad). After blocking for $1 \mathrm{~h}$ with $5 \%$ nonfat dry milk in $1 \times$ TBS with $0.1 \%$ Tween 20 (TTBS), membranes were incubated overnight at $4{ }^{\circ} \mathrm{C}$ with different primary antibodies: anti-Erk1/2 (Erk1/2), anti-phospho-Erk1/2 $\left(\mathrm{Thr}^{202} / \mathrm{Tyr}^{204}\right)$ (p-Erk1/2), anti-Akt (Akt), anti-phospho-Akt $\left(\mathrm{Ser}^{473}\right)$ (p-Akt), anti-P70S6K (P70S6K), anti-phospho-P70S6K $\left(\mathrm{Thr}^{389}\right) \quad(\mathrm{p}-\mathrm{P} 70 \mathrm{~S} 6 \mathrm{~K})$, anti-VEGF (VEGF), anti-VEGFR1 (VEGFR1), anti-VEGFR2 (VEGFR2), anti-phospho-VEGFR2 (Tyr ${ }^{175}$ ) (p-VEGFR2) (Cell Signaling Technology, Beverly, MA, USA), all diluted 1:1000 in TTBS and BSA 5\%, and monoclonal anti- $\beta$-actin (1:5000; Sigma-Aldrich). Membranes were then incubated with HRP-labeled goat antimouse or antirabbit secondary antibody (Jackson Immunoresearch Laboratories, West Grove, PA, USA) for $1 \mathrm{~h}$. Immunoreactivity was detected with LiteAblot Extend Long Lasting Chemiluminescent Substrate (EuroClone, Pero, MI, Italy). Films were scanned and band intensity quantified with ImageJ Software $1.44 \mathrm{p}$. All experiments were performed in triplicate.

\section{Flow cytometry analysis for apoptotic and cell cycle studies}

SW13 and H295R cells were incubated overnight in $0.1 \%$ FBS-containing medium and then treated with sorafenib $(5 \mu \mathrm{M})$ and/or everolimus $(9 \mu \mathrm{M})$ for 6 and $24 \mathrm{~h}$. Apoptosis was examined by Annexin V-FICT Apoptosis detection Kit (Bender MedSystems, Boehringer Ingelheim, Vienna, Austria ) in accordance with the manufacturer's protocol. Cell cycle status was studied by propidium iodide (PI) staining. Both H295R and SW13 were plated in six-well plates at a density of $1 \times 10^{6}$ cells/well and were either untreated or treated for 6 and $24 \mathrm{~h}$ with sorafenib $5 \mu \mathrm{M}$ and/or everolimus $9 \mu \mathrm{M}$ in $0.1 \%$ FBS, trypsinized, and harvested by centrifugation. Cells were resuspended in ice-cold PBS and fixed in $70 \%$ ice-cold ethanol followed by an overnight incubation at $-20^{\circ} \mathrm{C}$. After washing, cells were stained with PI solution $(50 \mu \mathrm{g} / \mathrm{ml}$ PI, $10 \mu \mathrm{g} / \mathrm{ml}$ RNaseA) and incubated for $1 \mathrm{~h}$ at $37^{\circ} \mathrm{C}$ in darkness. Analysis of apoptosis and cell cycle, performed in triplicate, was carried out by Cytomics FC500 (Beckman Coulter, Fullerton, CA, USA).

\section{In vivo therapeutic experiments and imaging}

In vivo experiments were performed using 6- to 8-week-old female severe combined immunodeficiency (SCID) and $\mathrm{Rag}^{-1-} / \gamma_{\mathrm{c}}^{-1-}$ mice that were housed in our specific pathogen-free animal facility. Procedures involving animals and their care were in conformity with institutional guidelines that comply with national and international law and policies (D.L. 116/92 and subsequent implementing circulars), and experimental protocols were approved by the Local Ethics Committee of Padua University (CEASA). To track tumor growth in vivo, SW13 and H295R cells were transduced with a lentiviral vector coding for the firefly luciferase reporter gene (Keyaerts et al. 2008). Bioluminescence (BLI) images were acquired at several time points after in vivo cell injection using the IVIS Lumina II Imaging System (Caliper Life Sciences, Alameda, CA, USA). Ten minutes before each imaging session, animals were anesthetized and administered with $150 \mathrm{mg} / \mathrm{kg}$ D-luciferin (Caliper Life Sciences) i.p. in PBS. A constant region of interest was drawn over the abdomen of animals and the signal intensity measured as radiance (total photon/s per $\mathrm{cm}^{2}$ per sr) with LivingImage Software (Caliper Life Sciences). For tumor induction, SW13 $\left(5 \times 10^{6} \%\right.$ mouse) and $\mathrm{H} 295 \mathrm{R}$ cells $\left(6 \times 10^{6} /\right.$ mouse $)$ were inoculated subcutaneously into the right flank of SCID and $\mathrm{Rag}^{-1-} / \gamma_{\mathrm{c}}^{-1-}$ mice, and treatments were started when median tumor volume was in the range of $40-80 \mathrm{~mm}^{3}$. Sorafenib and everolimus were given at a dose of 45 and $5 \mathrm{mg} / \mathrm{kg}$, respectively, thrice weekly by gavage, alone or in combination. Tumor growth and response to therapy were monitored by BLI and recording survival; at the end of experiments, animals were killed and the xenografts excised and conserved for histology.

\section{Statistical analysis}

Differences of gene expression, relationships between gene expression and clinical data, and a comparison of drug treatment in the cells were performed by the Wilcoxon two-sample test and Kruskal-Wallis test followed by Dunn test for pairwise comparisons in case of $P<0.05$. Band quantifications were performed with ImageJ (Abramoff et al. 2004) and paired $t$-test was used for statistical analysis. The data are presented as mean \pm s.D. For in vivo experiments, Kaplan-Meier product limit method was performed to estimate the survival curves, and comparison of survival between groups was carried out using the log-rank test. 
All $P$ values were based on a two-sided testing, and statistical analyses were conducted with the MedCalc statistical package (version 8.1; MedCalc Software, Mariakerke, Belgium). Differences were considered significant when $P<0.05$.

\section{Results}

\section{Expression analysis of VEGFRs in ACTs}

Gene expression of VEGFRs was analyzed in ACC, APA, and CPA. We found VEGF over-expression in ACC group $(P=0.049)$ and APA group $(P=0.025)$ if compared with NA group. No significant increase in VEGF was found in CPA group compared with NA group. VEGFR1 and 2 were particularly over-expressed in some ACC and APA samples, but there was not a significant difference between ACC, APA, CPA groups, and NA group (Fig. 1A). Expression data were confirmed by IHC, which identified VEGF and VEGFR2 proteins in both APA and ACC, albeit at variable expression rates (Fig. 1B). Finally, expression of VEGF, VEGFR1, and VEGFR2 proteins in SW13 and H295R cells was demonstrated by WB analysis (Fig. 1C).

Association of VEGF, VEGFR1, and VEGFR2 expression data with clinical characteristics of ACC, such as sex, age of onset, stage, and progression of disease and death, showed a significant inverse relationship between stage of the disease and VEGFR $1 \quad(P=0.03)$ and VEGFR2 $(P=0.02)$ expression. No other significant association was found.

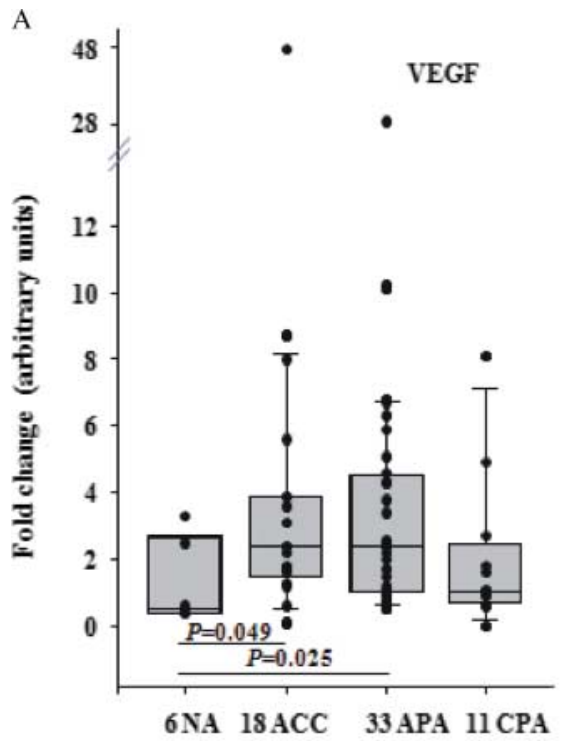

B

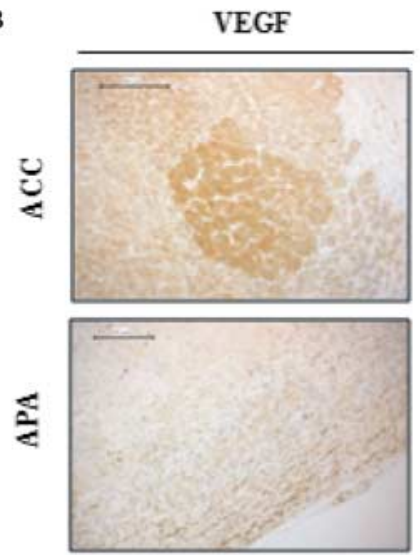

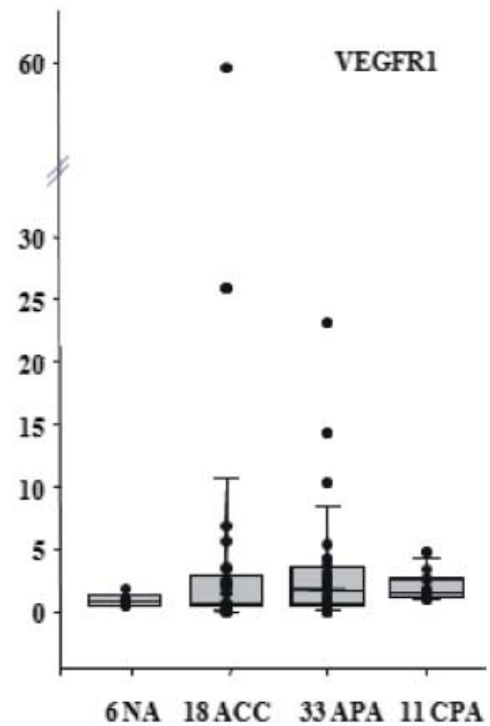

VEGFR2
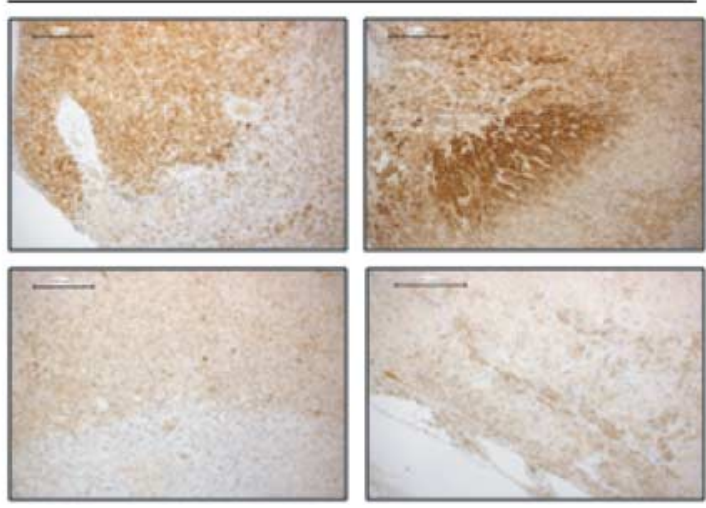

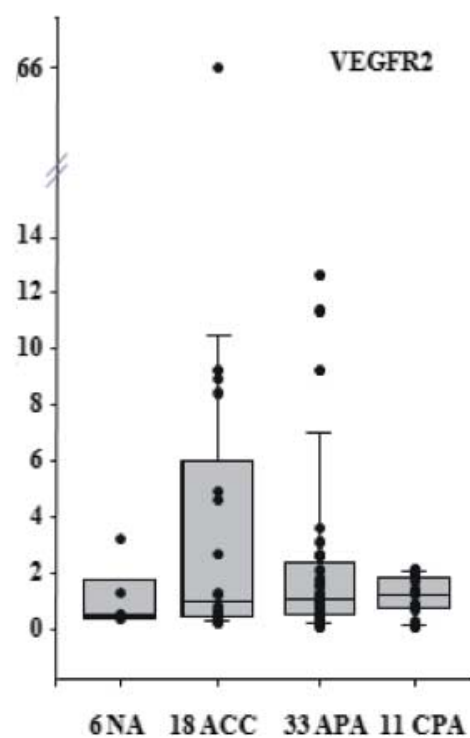

C

\section{SW13 H295R}

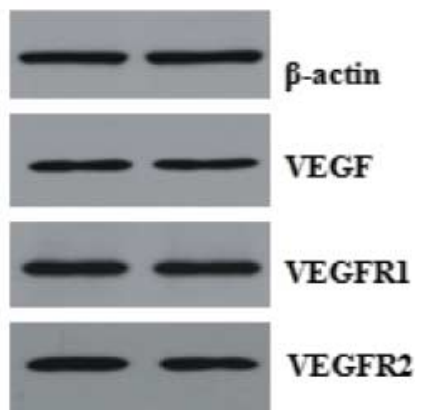

Figure $1 \mathrm{mRNA}$ and protein expression studies on adrenocortical samples. (A) Expression of VEGF, VEGFR1, and VEGFR2 mRNA in ACT. The graph represents $Y$-value median-quartile boxplots with decile error bars. (B) Immunohistochemical detection of VEGF and VEGR2 in representative ACT. (C) WB analysis of VEGF, VEGFR1, and VEGFR2 proteins in H295R and SW13 cells. 


\section{Sorafenib and everolimus inhibit ACC cell lines growth}

The effects of sorafenib and everolimus on SW13 and H295R cell viability were evaluated after 24 and $72 \mathrm{~h}$ exposure by comparison with untreated control cells. Individually, both drugs exerted dose-dependent cytotoxicity on SW13 and H295R both at 24 and $72 \mathrm{~h}$ (Fig. 2A and B). Everolimus was effective at $1 \mathrm{nM}$ at both time points and against both cell types (Fig. 2A), with a statistically significant effect $(P<0.01)$ at all drug concentrations. In contrast, responsiveness to sorafenib differed between H295R and $\mathrm{SW} 13$ cells. While the $\mathrm{IC}_{50}$ of sorafenib was between 0.1 and $0.3 \mu \mathrm{M}$ for SW13 at both 24 and $72 \mathrm{~h}, \mathrm{IC}_{50}$ was never reached in $\mathrm{H} 295 \mathrm{R}$ at any drug concentration after $24 \mathrm{~h}$ of exposure; prolonging the drug incubation time led to a marked increase in cytotoxicity with an $\mathrm{IC}_{50}$ between 0.3 and $0.5 \mu \mathrm{M}$ and therefore only slightly inferior to that for SW13. The combination of everolimus over a concentration range of $1 \mathrm{nM}-10 \mu \mathrm{M}$ with a single concentration of sorafenib $(0.1 \mu \mathrm{M})$ produced a further reduction of SW13 cell viability, which was statistically significant between 0.3 and $10 \mu \mathrm{M}$ at $24 \mathrm{~h}$ and from $1 \mathrm{nM}$ to $10 \mu \mathrm{M}$ at $72 \mathrm{~h}$ of treatment (Fig. 2C
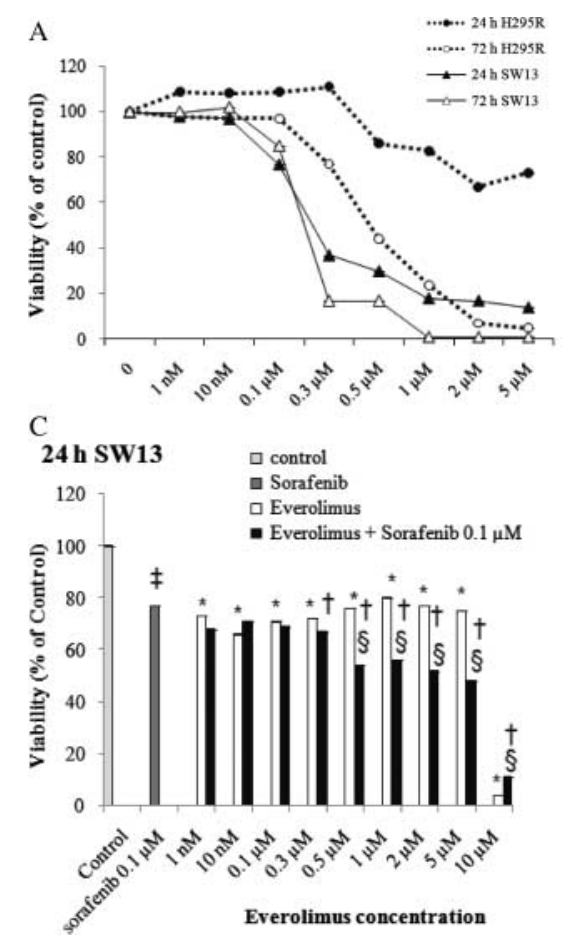

and D); conversely, no significant effects were observed on H295R with combination treatment (data not shown).

\section{Assessment of the effects of sorafenib and everolimus on intracellular pathways in ACC cell lines}

IP analysis showed that VEGF-induced phosphorylation of VEGFR2 was strikingly reduced by sorafenib treatment in both SW13 and H295R cells (Fig. 3A). Moreover, analysis of intracellular pathways affected by the drugs showed that sorafenib $(5 \mu \mathrm{M})$ markedly reduced p-Akt, p-ERK1/2, and p-P70S6K in SW13, while only p-ERK seemed to be reduced in H295R (Fig. 3B). On the other hand, everolimus abolished P70S6K phosphorylation in both SW13 and H295R, while it had no effect on p-ERK and only slightly reduced p-Akt at the highest drug concentration (Fig. 3C).

\section{Sorafenib and everolimus are active in primary ACT cultures}

In primary adrenocortical cell cultures, we found a significant growth inhibitory response to drug
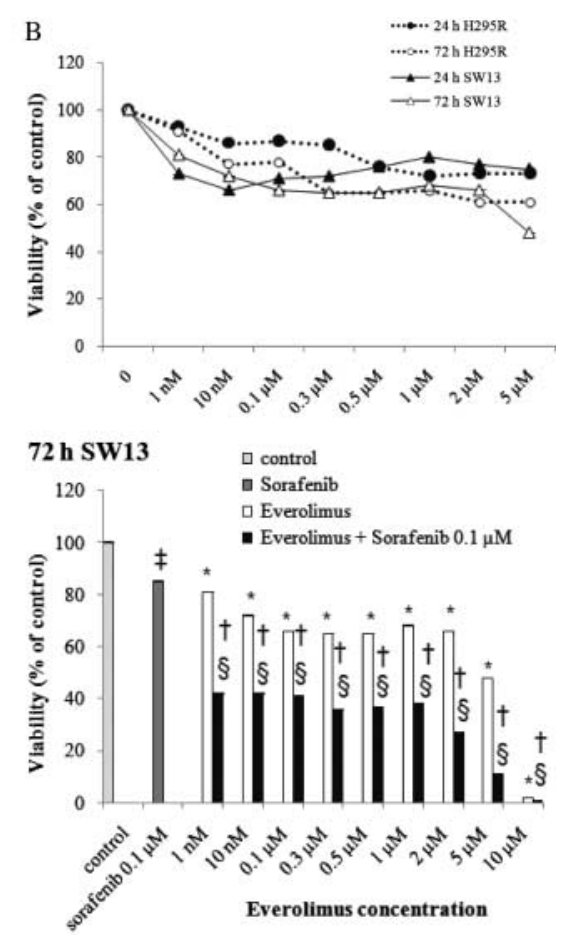

Figure 2 Everolimus and sorafenib growth inhibitory activity in ACC cell lines. Effects of everolimus (A) and sorafenib (B) on cell viability in H295R and SW13 at 24 and $72 \mathrm{~h}$ of treatment. (C) Cytotoxicity of SW13 treated with the combination of everolimus and sorafenib at 24 and $72 \mathrm{~h}$. ${ }^{\ddagger}$ Sorafenib vs control, $P<0.05$; ${ }^{\dagger}$ everolimus + sorafenib vs sorafenib, $P<0.05$; *everolimus vs control, $P<0.05$; $\$$ everolimus + sorafenib vs everolimus, $P<0.05$. All experiments were performed in quadruplicate. 

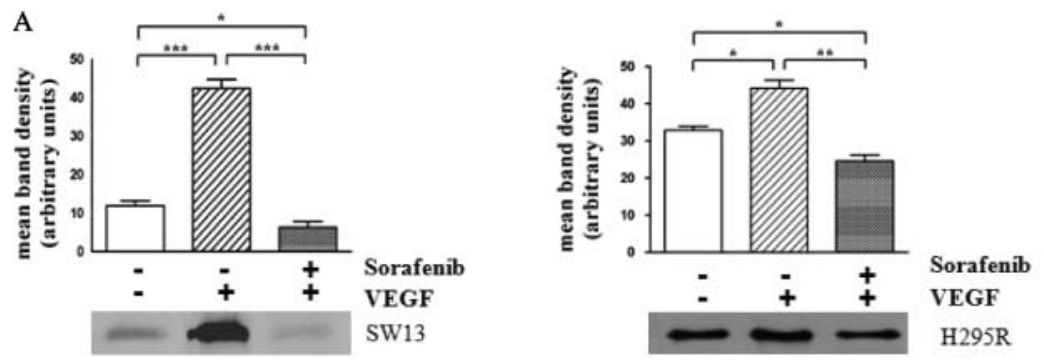

B
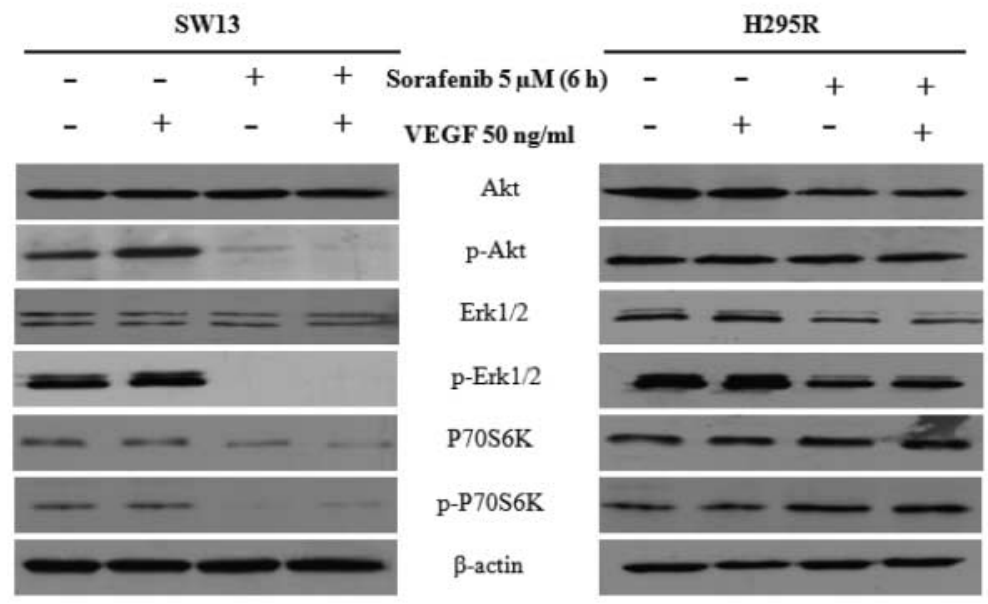

C

SW13
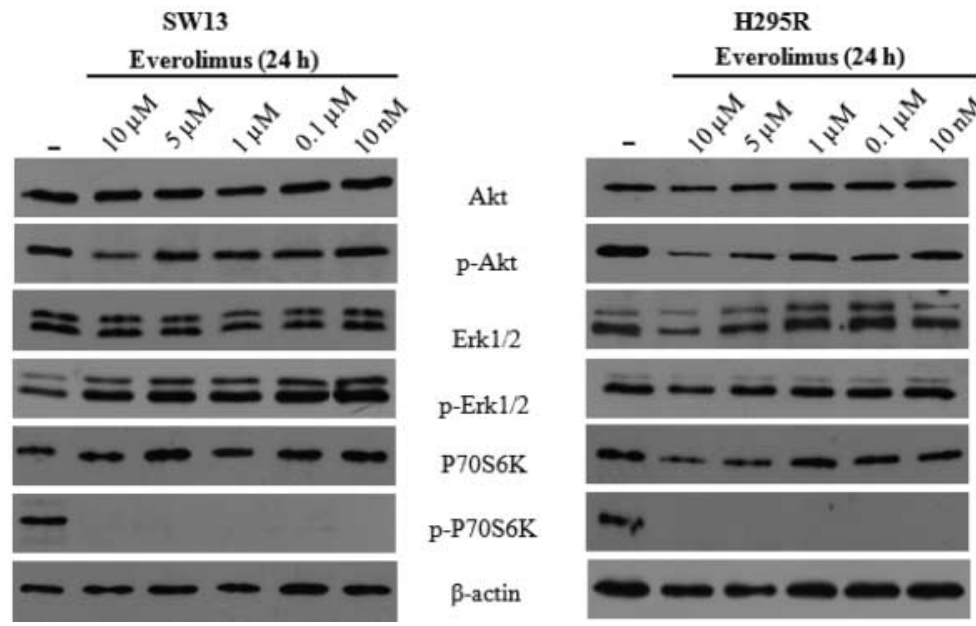

Figure 3 Drug effects on the ACC cell line intracellular pathways. (A) Antiphospho-VEGFR2 IP in the presence or absence of VEGF and sorafenib with relative histogram quantification $\left({ }^{\star} P<0.05 ;{ }^{* \star} P<0.01 ;{ }^{* \star *} P<0.001\right)$. (B) Expression of Akt, $p-A k t$, Erk1/2, p-Erk1/2, P70S6K, p-P70S6K, and $\beta$-actin proteins in SW13 and H295R after $6 \mathrm{~h}$ of treatment with/without sorafenib in the presence or absence of VEGF stimulation. (C) Expression of Akt, p-Akt, Erk1/2, p-Erk1/2, P70S6K, p-P70S6K, and $\beta$-actin proteins in SW13 and H295R after $24 \mathrm{~h}$ of treatment with everolimus at various concentrations. All experiments were performed in triplicate.

treatment in three ACCs and three APA; two ACCs were unresponsive (Fig. 4A, B and C). Biochemical analysis of proteins purified from one ACC treated for $6 \mathrm{~h}$ with either sorafenib $(5 \mu \mathrm{M})$ or everolimus $(0.1 \mu \mathrm{M})$ showed an almost complete inhibition of p-Akt and p-P70S6K and a marked reduction in p-ERK with sorafenib (Fig. 4D).

\section{Sorafenib and everolimus do not alter cell cycle but induce apoptosis in ACC cell lines}

On fluorescence activated cell sorter (FACS) analysis of SW13 and H295R cell lines after 6 and $24 \mathrm{~h}$ of exposure to everolimus or sorafenib, no changes in cell cycle stage were seen. Increased Annexin V-FITCpositive/PI-negative cell (early apoptosis) and Annexin 

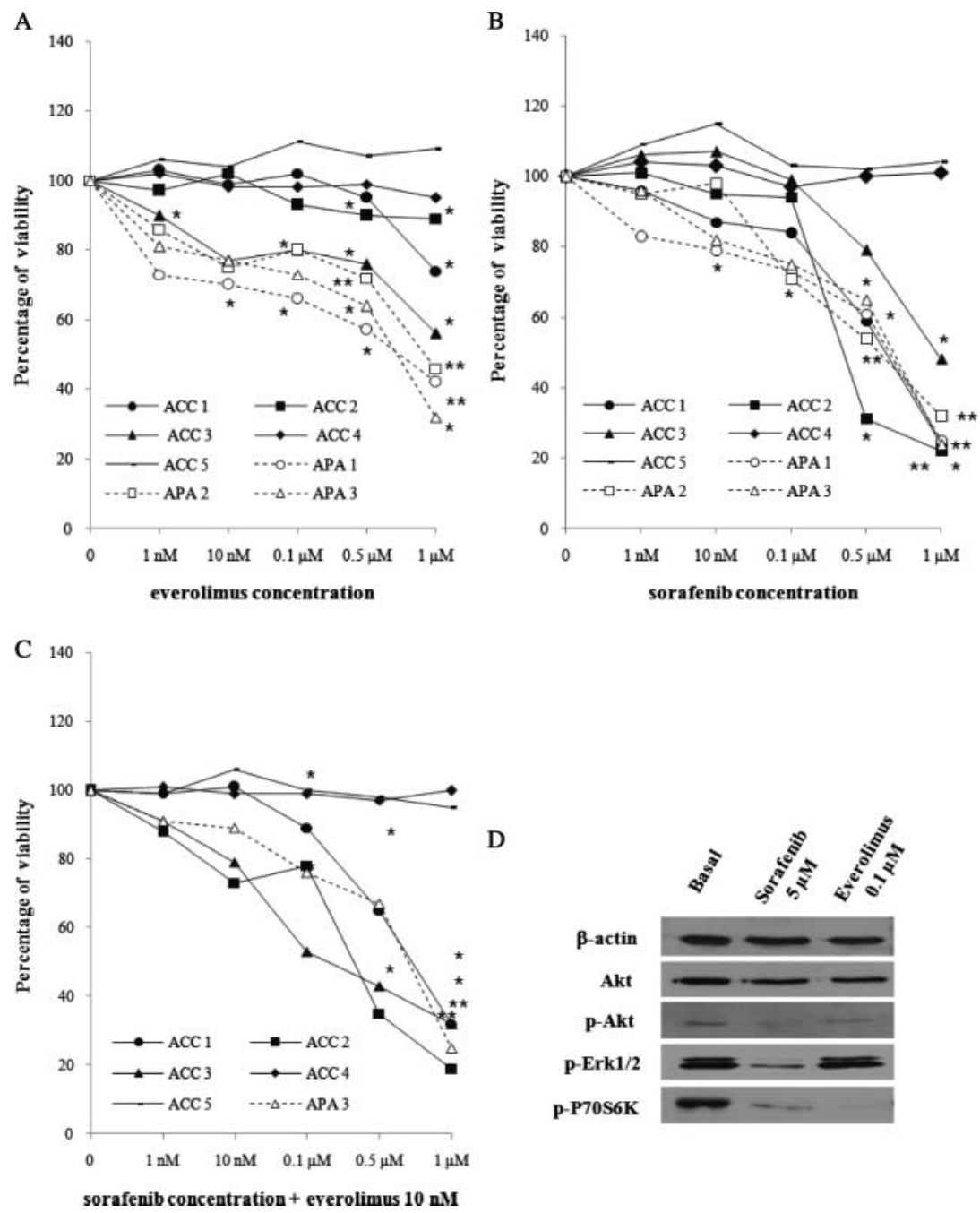

Figure 4 Effects of everolimus and sorafenib on primary adrenocortical cell cultures at $24 \mathrm{~h}$. Cytotoxicity of everolimus (A), sorafenib (B), and in combination (C) in five ACCs (ACC1-5) and three APA (APA1-3). ${ }^{\star} P<0.05 ;{ }^{\star \star} P<0.005$. All experiments were performed in quadruplicate. (D) WB analysis of Akt, p-Akt, p-Erk1/2, p-P70S6K, and $\beta$-actin in one primary adrenocortical cell culture of ACC treated with sorafenib and everolimus.

V-FITC-positive/PI-positive cell (late apoptosis or necrosis) signals were detected in SW13 treated with either sorafenib or everolimus at $6 \mathrm{~h}$ (Fig. 5A). A minor apoptotic effect than SW13 was also evident in H295R when treated with sorafenib (Fig. 5B).

\section{Combination of sorafenib and everolimus inhibits tumor growth in vivo}

The in vivo therapeutic activity of sorafenib and everolimus, alone or in combination, was evaluated in xenograft models of established s.c. tumors comprising luciferase-transduced cancer cells and assessed by bioluminescence and survival. Sorafenib monotherapy showed no significant activity on either SW13 and H295R xenografts, whereas administration of everolimus alone delayed SW13 tumor growth but was ineffective against H295R xenografts (Fig. 6A and $\mathrm{B})$. On the other hand, combination therapy produced remarkable tumor growth inhibitory effects on both SW13 and H295R xenografts, as shown by the significant reduction of the average bioluminescence of tumors from treated animals compared with the placebo (Fig. 6A and B). Other than reducing tumor growth, pharmacological treatments affected median survival; in SW13 and H295R xenografts, median survivals were 44, 30, 47, and 53 days and 53, 48, 63, and 70 days for mice receiving placebo, sorafenib, everolimus, or combined treatment respectively, again indicating a synergistic action of the combination treatment. 

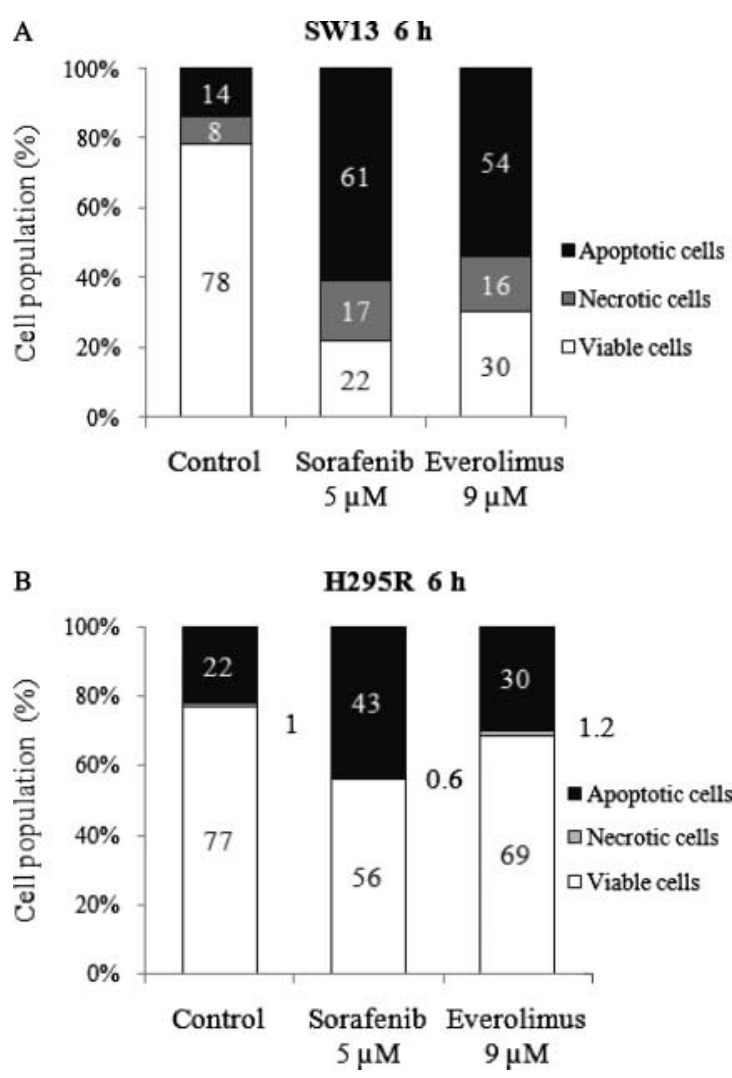

Figure 5 Apoptosis analysis in ACC cell lines. Apoptosis analysis was performed cytofluorimetrically in SW13 (A) and H295R (B) by Annexin V-FITC staining after $6 \mathrm{~h}$ of treatment with sorafenib and everolimus.

\section{Discussion}

This study investigates the expression of VEGF, VEGFR1, and VEGFR2 in ACTs and reports the effects of two promising drugs (sorafenib and everolimus) on adrenocortical cell proliferation, apoptosis, and cell cycle modification in vitro, as well as on tumor mass reduction and survival in xenograft mouse models in vivo.

The adult adrenal cortex is a highly vascularized organ that abundantly expresses VEGF, possibly to maintain a high density of stable fenestrated microvessels (Shweiki et al. 1993). Our experiments confirm that VEGF is expressed in adrenals, with expression levels similar in normal adrenal, lung, and kidney (data not shown), where VEGF is reported to be most abundant (Ferrara \& Davis-Smyth 1997). This finding supports the rationale for testing antiangiogenic drugs in ACC. VEGF is a very important mediator of angiogenesis in solid tumors and with insulin-like growth factor is an autocrine/paracrine regulator of tumor cell growth in many different cancers, including ACTs (De Martino et al. 2010).
We found the presence of VEGFRs in all adrenocortical masses, with increased expression of VEGF mRNA in some ACCs and APA compared with NA. We also showed by IHC very high levels of VEGF and VEGFR2 in ACC compared with APA, in line with the previous data reporting higher levels of VEGF protein in ACC than in benign adenomas (Feige 2009, Xu et al. 2011); these results support the hypothesis that VEGF is upregulated at the transcriptional level in these tumors (Feige 2009). Moreover, in ACC, increased cytoplasmatic VEGF concentrations have been reported (de Fraipont et al. 2000). Such an increment has been found in a large number of human tumors and seems to be important to induce tumor growth and metastasis formation (Hanahan \& Folkman 1996). These lines of evidence thus suggest that therapeutic neutralization of VEGF may be useful approach in the treatment of ACC. In addition, a recent work describes the absence of bevacizumab activity, a monoclonal antibody directed to VEGF, in patients with very advanced ACC (Wortmann et al. 2010). Otherwise, we used two drugs (everolimus and sorafenib) that act on the phosphorylation of different molecular targets, making our research different and innovative.

As VEGF acts through the activation of its receptors, the evidence that the ACTs express high levels of VEGFR2 led us to use a tyrosine kinase inhibitor specific for VEGFR2, sorafenib, to validate its antitumor effect in ACC. Tyrosine kinase receptors activate at least two survival pathways that are able to induce cell proliferation and to protect cancer cells from apoptosis: PI3K/AKT and MAPK/ERK. As previously reported (Wilhelm et al. 2008), we demonstrated that sorafenib inhibits the phosphorylation of VEGFR2 in adrenocortical cells; besides, it also decreases the p-AKT and p-ERK, with marked reductions in H295R and SW13 cell viability. Moreover, sorafenib increases apoptosis and necrosis particularly in SW13 without altering the cell cycle in either SW13 or H295R cells. We believe that sorafenib, acting to inhibit both angiogenesis and cell proliferation, and driven by the VEGF/VEGFR2 autocrine loop in tumor cells (Graells et al. 2004), could thus represent a promising drug in the treatment of advanced ACC unresponsive to traditional treatment, as previously reported (Butler et al. 2009).

Most of our adrenocortical cancer patients presented with metastases, thus we might expect high levels of $V E G F$ mRNA expression in these tumors. Our findings thus confirm the importance of VEGF in adrenocortical tumorigenesis. Local hypoxia, a major inducer of VEGF gene expression (Ferrara \& Davis-Smyth 1997), is probably responsible for VEGF over-expression 

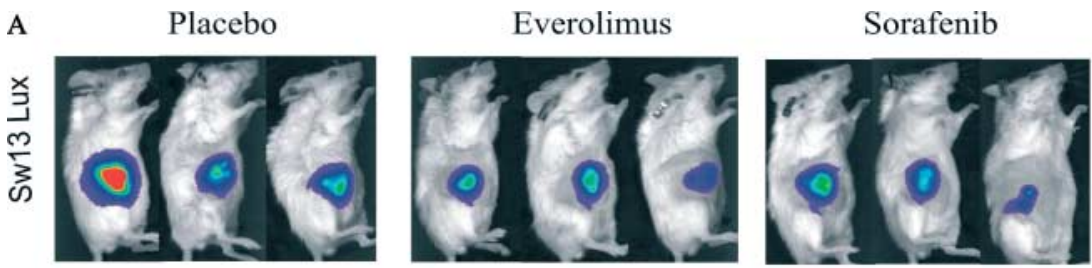

Everolimus+Sorafenib
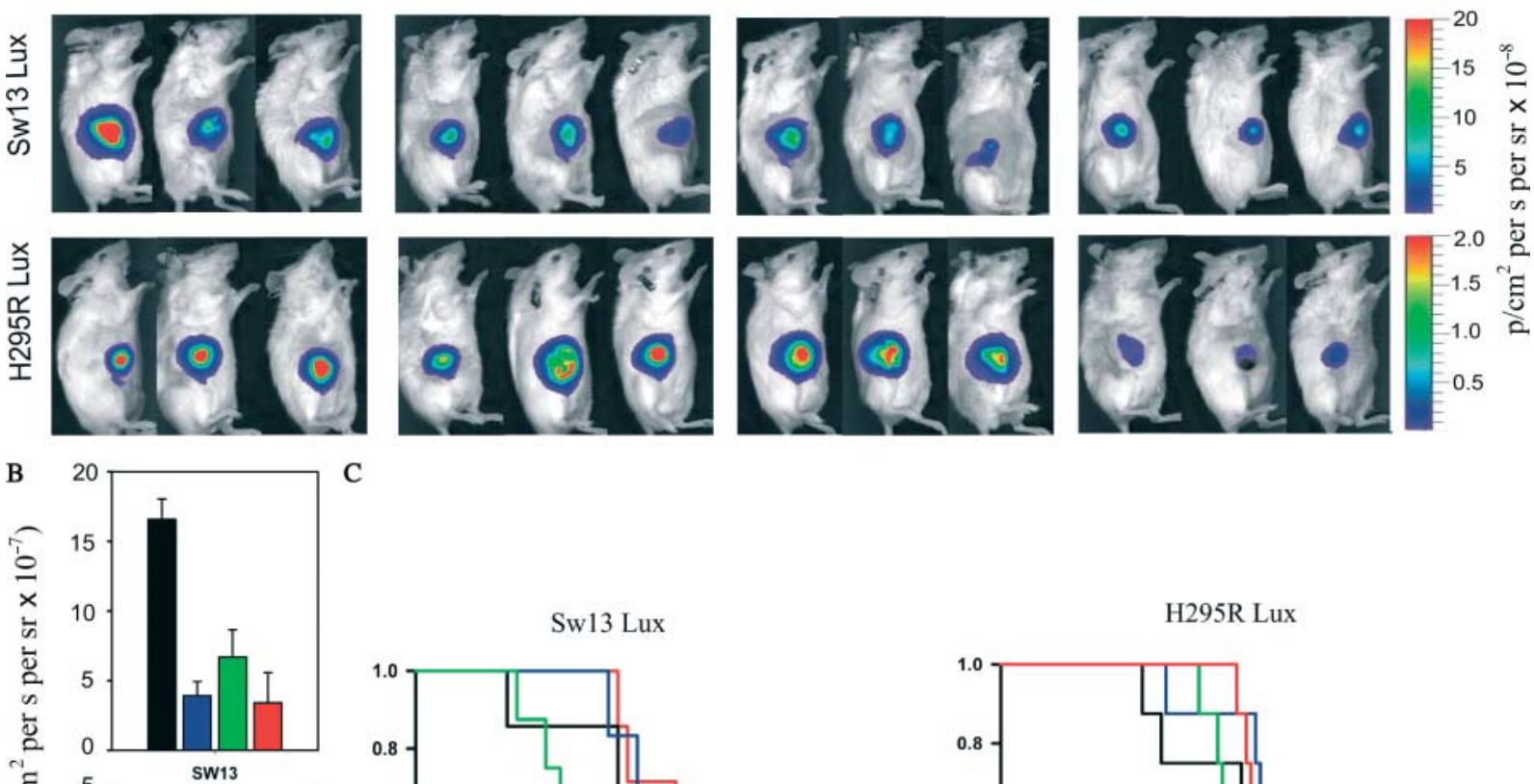

C
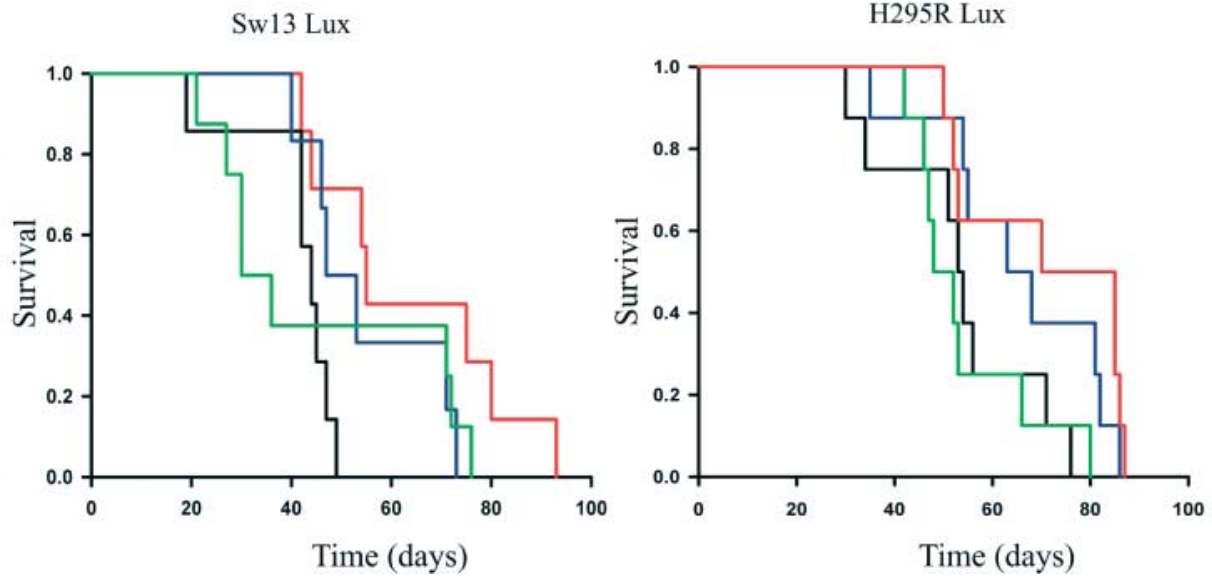

Figure 6 Assessment of in vivo tumor growth and response to therapy. (A) Bioluminescence imaging of treated or untreated mice bearing s.c. tumors induced by inoculation of luciferase-transduced SW13 (upper panels) or H295R cells (lower panels). Panels show three representative mice per group imaged 4 weeks after tumor injection. (B) Cumulative photon emission from mice treated as in A; graphs report mean data \pm S.D. obtained from eight mice per group (black bar, placebo; blue bar, everolimus; green bar, sorafenib; red bar, combined treatment) at day 28 after tumor inoculation. Statistical analysis: SW13, sorafenib vs placebo, $P=0.267$; everolimus vs placebo, $P=0.029$; combined treatment vs placebo, $P=0.011$; H295R, sorafenib vs placebo, $P=0.400$; everolimus vs placebo, $P=0.714$; combined treatment vs placebo, $P=0.024$. (C) Kaplan-Meier survival curves of mice inoculated with SW13 or H295R. Mice received placebo (controls, $n=8$, black lines), everolimus ( $n=8$, blue lines), sorafenib $(n=8$, green lines), or a combination of the two drugs (red lines). Statistical analysis: SW13, sorafenib vs placebo, $P=0.051$; everolimus vs placebo, $P=0.053$; combined treatment vs placebo, $P=0.011$; H295R, sorafenib vs placebo, $P=0.898$; everolimus vs placebo, $P=0.079$; combined treatment vs placebo, $P=0.055$.

in ACT. The elevated expression of VEGF in APA suggests an increased angiogenic potential of these lesions, although protein transcription is the ultimate determinant in this process (Feige 2009); the similar $V E G F$ expression in normal adrenals and CPA confirm the findings of Bernini et al. (2002). We also observed that the expression of VEGFRs in three patients with stage II cancer was higher than all the other ACC patients; probably, late tumors no longer need to express the VEGFR2, but the small number of patients does not allow us to hypothesize a possible explanation. In fact, the correlation of VEGFR with ACC stage has to be considered cautiously given the very small number of stage II patients.

Everolimus acts downstream the PI3K/AKT pathway, targeting the mTOR protein. The antiproliferative effect of everolimus was initially investigated in a mixed panel of tumor cell lines (Fasolo \& Sessa 2008); its antiangiogenic activity has been demonstrated (Guba et al. 2002), and very positive therapeutic effects have been reported in patients with advanced renal cell carcinoma (Agarwala \& Case 2010). 
Based on these premises, we verified the effect of everolimus against AT, and following Doghman et al. (2010), we found a significantly reduced proliferation in H295R and SW13 cells and in some but not in all adrenal cancers in culture. We also showed that everolimus markedly inhibited the mTOR downstream effector p70S6K, slightly inhibited p-AKT in both cell lines, but had no effect on p-ERK. Everolimus induced marked apoptosis in SW13 cells, whereas H295R appeared insensitive. Probably, the different features of these two adrenocortical cell lines may play a role in the differential response to this agent.

We also studied the efficacy of sorafenib and everolimus in primary adrenocortical cell cultures. We found a positive response in all APA and in three of five ACCs, thus emphasizing the sensitivity of some adrenocortical cells to these drugs. Interestingly, the two unresponsive cancers had relatively low expression of VEGFR2 compared with NA, whereas the responsive tumors showed VEGFR2 expression comparable with NA.

We also obtained interesting results in the in vivo experiments, with a significant response in adrenocortical xenograft mouse models treated with single drug and in particular with their combination. We observed a significant size reduction with the combination of everolimus plus sorafenib both in SW13 and H295R xenograft mouse models, in line with previous experiments in hepatocellular carcinoma (Huynh et al. 2009). Interestingly, the combined treatment showed similar results in both in vitro and in vivo experiments; the addition of everolimus to sorafenib potentiated the effect of the latter in in vitro experiments on SW13 cells, and combined use of the drugs significantly reduced the tumor masses in SW13 xenograft mice. Combined treatment also led to a significant increase in median survival in SW13 models. Notably, everolimus alone significantly reduced tumor growth in SW13 xenografts, in accordance with the very high percentage of apoptosis seen in in vitro experiments.

Overall, our results stress the importance of angiogenic pathways in ACTs and in particular highlight the possibility that antiangiogenic drugs that may have considerable therapeutic potential for such tumors. Moreover, the synergistic effect obtained by the combination treatment with sorafenib and everolimus, in comparison to single agent therapy, suggests that simultaneous inhibition of several signaling pathways may be a more effective anticancer strategy in these very aggressive tumors.

\section{Declaration of interest}

The authors declare that there is no conflict of interest that could be perceived as prejudicing the impartiality of the research reported.

\section{Funding}

This work was supported by the AIRC association (Associazione Italiana Ricerca sul Cancro - grant number 5250) and ENS@T-CANCER (European Network for the Study of Adrenal Tumours - grant agreement number 259735).

\section{Acknowledgements}

The authors thank Dr C Radu for help with flow cytometry analysis, Novartis for gift of everolimus, and Bayer Corporation for gift of sorafenib.

\section{References}

Abramoff MD, Magalhaes PJ \& Ram SJ 2004 Image processing with ImageJ. Biophotonics International $1136-42$.

Agarwala SS \& Case S 2010 Everolimus (RAD001) in the treatment of advanced renal cell carcinoma: a review. Oncologist 15 236-245. (doi:10.1634/theoncologist. 2009-0141)

Albiger NM, Occhi G, Mariniello B, Iacobone M, Favia G, Fassina A, Faggian D, Mantero F \& Scaroni C 2007 Food-dependent Cushing's syndrome: from molecular characterization to therapeutical results. European Journal of Endocrinology 157 771-778. (doi:10.1530/ EJE-07-0253)

Allolio B \& Fassnacht M 2006 Clinical review: adrenocortical carcinoma: clinical update. Journal of Clinical Endocrinology and Metabolism 91 2027-2037. (doi:10.1210/jc.2005-2639)

Bachelder RE, Crago A, Chung J, Wendt MA, Shaw LM, Robinson G \& Mercurio AM 2001 Vascular endothelial growth factor is an autocrine survival factor for neuropilin-expressing breast carcinoma cells. Cancer Research 61 5736-5740.

Bernini GP, Moretti A, Bonadio AG, Menicagli M, Viacava P, Naccarato AG, Iacconi P, Miccoli P \& Salvetti A 2002 Angiogenesis in human normal and pathologic adrenal cortex. Journal of Clinical Endocrinology and Metabolism 87 4961-4965. (doi:10.1210/jc.2001-011799)

Butler C, Butler WM \& Rizvi AA 2009 Sustained remission with the kinase inhibitor sorafenib in stage IV metastatic adrenocortical carcinoma. Endocrine Practice 26 1-19. (doi:10.4158/EP09295.CR)

Crew JP, O’Brien T, Bradburn M, Fuggle S, Bicknell R, Cranston D \& Harris AL 1997 Vascular endothelial growth factor is a predictor of relapse and stage progression in superficial bladder cancer. Cancer Research 57 5281-5285. 
De Martino MC, van Koetsveld PM, Pivonello R \& Hofland LJ 2010 Role of the mTOR pathway in normal and tumoral adrenal cells. Neuroendocrinology 92 (Suppl 1) 28-34. (doi:10.1159/000314280)

Doghman M, El Wakil A, Cardinaud B, Thomas E, Wang J, Zhao W, Peralta-Del Valle MH, Figueiredo BC, Zambetti GP \& Lalli E 2010 Regulation of insulin-like growth factor-mammalian target of rapamycin signaling by microRNA in childhood adrenocortical tumors. Cancer Research 70 4666-4675. (doi:10.1158/0008-5472.CAN09-3970)

Fasolo A \& Sessa C 2008 mTOR inhibitors in the treatment of cancer. Expert Opinion on Investigational Drugs 17 1717-1734. (doi:10.1517/13543784.17.11.1717)

Feige JJ 2009 Angiogenesis in adrenocortical physiology and tumor development. Annales d'Endocrinologie 70 153-155. (doi:10.1016/j.ando.2009.02.005)

Ferrara N \& Davis-Smyth T 1997 The biology of vascular endothelial growth factor. Endocrine Reviews 18 4-25. (doi:10.1210/er.18.1.4)

Ferrara N, Gerber HP \& LeCouter J 2003 The biology of VEGF and its receptors. Nature Medicine 9 669-676. (doi:10.1038/nm0603-669)

de Fraipont F, El Atifi M, Gicquel C, Bertagna X, Chambaz EM \& Feige JJ 2000 Expression of the angiogenesis markers vascular endothelial growth factor-A, thrombospondin-1, and platelet-derived endothelial cell growth factor in human sporadic adrenocortical tumors: correlation with genotypic alterations. Journal of Clinical Endocrinology and Metabolism 85 4734-4741. (doi:10.1210/jc.85.12.4734)

de Fraipont F, El Atifi M, Cherradi N, Le Moigne G, Defaye G, Houlgatte R, Bertherat J, Bertagna X, Plouin PF, Baudin E et al. 2005 Gene expression prolifing of human adrenocortical tumors using complementary deoxyribonucleic acid microarrays identifies several candidate genes as markers of malignancy. Journal of Clinical Endocrinology and Metabolism 90 1819-1829. (doi:10.1210/jc.2004-1075)

Graells J, Vinyals A, Figueras A, Llorens A, Moreno A, Marcoval J, Gonzalez FJ \& Fabra A 2004 Overproduction of VEGF concomitantly expressed with its receptors promotes growth and survival of melanoma cells through MAPK and PI3K signaling. Journal of Investigative Dermatology 123 1151-1161. (doi:10.1111/j.0022-202X. 2004.23460.x)

Grumbach MM, Biller BM, Braunstein GD, Campbell KK, Carney JA, Godley PA, Harris EL, Lee JK, Oertel YC, Posner MC et al. 2003 Managment of the clinically inapparent adrenal mass (incidentaloma). Annals of Internal Medicine 138 424-429. (doi:10.3275/7324)

Guba M, von Breitenbuch P, Steinbauer M, Koehl G, Flegel S, Hornung M, Bruns CJ, Zuelke C, Farkas S, Anthuber M et al. 2002 Rapamycin inhibits primary and metastatic tumor growth by antiangiogenesis: involvement of vascular endothelial growth factor. Nature Medicine 8 128-135. (doi:10.1038/nm0202-128)
Hanahan D \& Folkman J 1996 Patterns and emerging mechanisms of the angiogenic switch during tumorigenesis. Cell 86 353-364. (doi:10.1016/S00928674(00)80108-7)

Heikkilä P, Arola J, Voutilainen R, Salmenkivi K, Kahri AI \& Liu J 2000 Expression of vascular endothelial growth factor in human adrenals. Endocrine Research 26 867-871. (doi:10.3109/07435800009048610)

Houghton PJ 2010 Everolimus. Clinical Cancer Research: an Official Journal of the American Association for Cancer Research 16 1368-1372. (doi:10.1158/10780432.CCR-09-1314)

Huynh H, Ngo VC, Koong HN, Poon D, Choo SP, Thng CH, Chow P, Ong HS, Chung A \& Soo KC 2009 Sorafenib and rapamycin induce growth suppression in mouse models of hepatocellular carcinoma. Journal of Cellular and Molecular Medicine 13 2673-2683. (doi:10.1111/j.15824934.2009.00692.x)

Keating GM \& Santoro A 2009 Sorafenib: a review of its use in advanced hepatocellular carcinoma. Drugs 69 223-240. (doi:10.2165/00003495-200969020-00006)

Keyaerts M, Verschueren J, Bos TJ, Tchouate-Gainkam LO, Peleman C, Breckpot K, Vanhove C, Caveliers V, Bossuyt A \& Lahoutte T 2008 Dynamic bioluminescence imaging for quantitative tumour burden assessment using IV or IP administration of D: -luciferin: effect on intensity, time kinetics and repeatability of photon emission. European Journal of Nuclear Medicine and Molecular Imaging 35 999-1007. (doi:10.1007/s00259007-0664-2)

Leung DW, Cachianes G, Kuang WJ, Goeddel DV \& Ferrara N 1989 Vascular endothelial growth factor is a secreted angiogenic mitogen. Science 246 1306-1309. (doi:10.1126/ science.2479986)

Liu L, Cao Y, Chen C, Zhang X, McNabola A, Wilkie D, Wilhelm S, Lynch M \& Carter C 2006 Sorafenib blocks the RAF/MEK/ERK pathway, inhibits tumor angiogenesis, and induces tumor cell apoptosis in hepatocellular carcinoma model PLC/PRF/5. Cancer Research 66 11851-11858. (doi:10.1158/0008-5472. CAN-06-1377)

Mabuchi S, Altomare DA, Cheung M, Zhang L, Poulikakos PI, Hensley HH, Schilder RJ, Ozols RF \& Testa JR 2007a RAD001 inhibits human ovarian cancer cell proliferation, enhances cisplatin-induced apoptosis, and prolongs survival in an ovarian cancer model. Clinical Cancer Research: an Official Journal of the American Association for Cancer Research 13 4261-4270. (doi:10.1158/1078-0432.CCR06-2770)

Mabuchi S, Altomare DA, Connolly DC, Klein-Szanto A, Litwin S, Hoelzle MK, Hensley HH, Hamilton TC \& Testa JR 2007b RAD001(everolimus), delays tumor onset and progression in a transgenic mouse model of ovarian cancer. Cancer Research 67 2408-2413. (doi:10.1158/ 0008-5472.CAN-06-4490)

Mariniello B, Finco I, Sartorato P, Patalano A, Iacobone M, Guzzardo V, Fassina A \& Mantero F 2010 Somatostatin 
receptor expression in adrenocortical tumors and effect of a new somatostatin analog SOM230 on hormone secretion in vitro and in ex vivo adrenal cells. Journal of Endocrinological Investigation $\mathbf{7 0}$ 4666-4675.

Masood R, Cai J, Zheng T, Smith DL, Hinton DR \& Gill PS 2001 Vascular endothelial growth factor (VEGF) is an autocrine growth factor for VEGF receptor-positive human tumors. Blood 98 1904-1913. (doi:10.1182/blood. V98.6.1904)

Rahmani M, Davis EM, Bauer C, Dent P \& Grant S 2005 Apoptosis induced by the kinase inhibitor BAY 43-9006 in human leukemia cells involves down-regulation of Mcl-1 through inhibition of translation. Journal of Biological Chemistry 280 35217-35227. (doi:10.1074/ jbc.M506551200)

Shibusa T, Shijubo N \& Abe S 1998 Tumor angiogenesis and vascular endothelial growth factor expression in stage I lung adenocarcinoma. Clinical Cancer Research: an Official Journal of the American Association for Cancer Research 4 1483-1487.

Shinohara ET, Cao C, Niermann K, Mu Y, Zeng F, Hallahan DE \& Lu B 2005 Enhanced radiation damage of tumor vasculature by mTOR inhibitors. Oncogene 24 5414-5422. (doi:10.1038/sj.onc.1208715)

Shweiki D, Itin A, Neufeld G, Gitay-Goren H \& Keshet E 1993 Patterns of expression of vascular endothelial growth factor (VEGF) and VEGF receptors in mice suggest a role in hormonally regulated angiogenesis. Journal of Clinical Investigation 91 2235-2243. (doi:10.1172/JCI116450)

Wey JS, Stoeltzing O \& Ellis LM 2004 Vascular endothelial growth factor receptors: expression and function in solid tumors. Clinical Advances in Hematology and Oncology 2 37-45.

Wilhelm SM, Carter C, Tang L, Wilkie D, McNabola A, Rong $\mathrm{H}$, Chen $\mathrm{C}$, Zhang X, Vincent $\mathrm{P}, \mathrm{McHugh} \mathrm{M}$ et al.
2004 BAY 43-9006 exhibits broad spectrum oral antitumor activity and targets the RAF/MEK/ERK pathway and receptor tyrosine kinases involved in tumor progression and angiogenesis. Cancer Research 64 7099-7109. (doi:10.1158/0008-5472.CAN-04-1443)

Wilhelm S, Carter C, Lynch M, Lowinger T, Dumas J, Smith RA, Schwartz B, Simantov R \& Kelley S 2006 Discovery and development of sorafenib: a multikinase inhibitor for treating cancer. Nature Reviews Drug Discovery 5 835-844. (doi:10.1038/nrd2130)

Wilhelm SM, Adnane L, Newell P, Villanueva A, Llovet JM \& Lynch M 2008 Preclinical overview of sorafenib, a multikinase inhibitor that targets both Raf and VEGF and PDGF receptor tyrosine kinase signaling. Molecular Cancer Therapeutics 7 3129-3140. (doi:10.1158/15357163.MCT-08-0013)

Wortmann S, Quinkler M, Ritter C, Kroiss M, Johanssen S, Hahner S, Allolio B \& Fassnacht M 2010 Bevacizumab plus capecitabine as a salvage therapy in advanced adrenocortical carcinoma. European Journal of Endocrinology 162 349-356. (doi:10.1530/EJE-09-0804)

$\mathrm{Xu}$ YZ, Zhu Y, Shen ZJ, Sheng JY, He HC, Ma G, Qi YC, Zhao JP, Wu YX, Rui WB et al. 2011 Significance of heparanase-1 and vascular endothelial growth factor in adrenocortical carcinoma angiogenesis: potential for therapy. Endocrine 40 445-451. (doi:10.1007/s12020-011-9502-1)

Zacharieva S, Atanassova I, Nachev E, Orbetzova M, Kirilov G, Kalinov K \& Shigarminova R 2005 Markers of vascular function in hypertension due to Cushing's syndrome. Hormone and Metabolic Research 37 36-39. (doi:10.1055/ s-2005-861031)

Received in final form 14 May 2012

Accepted 6 June 2012

Made available online as an Accepted Preprint 6 June 2012 